
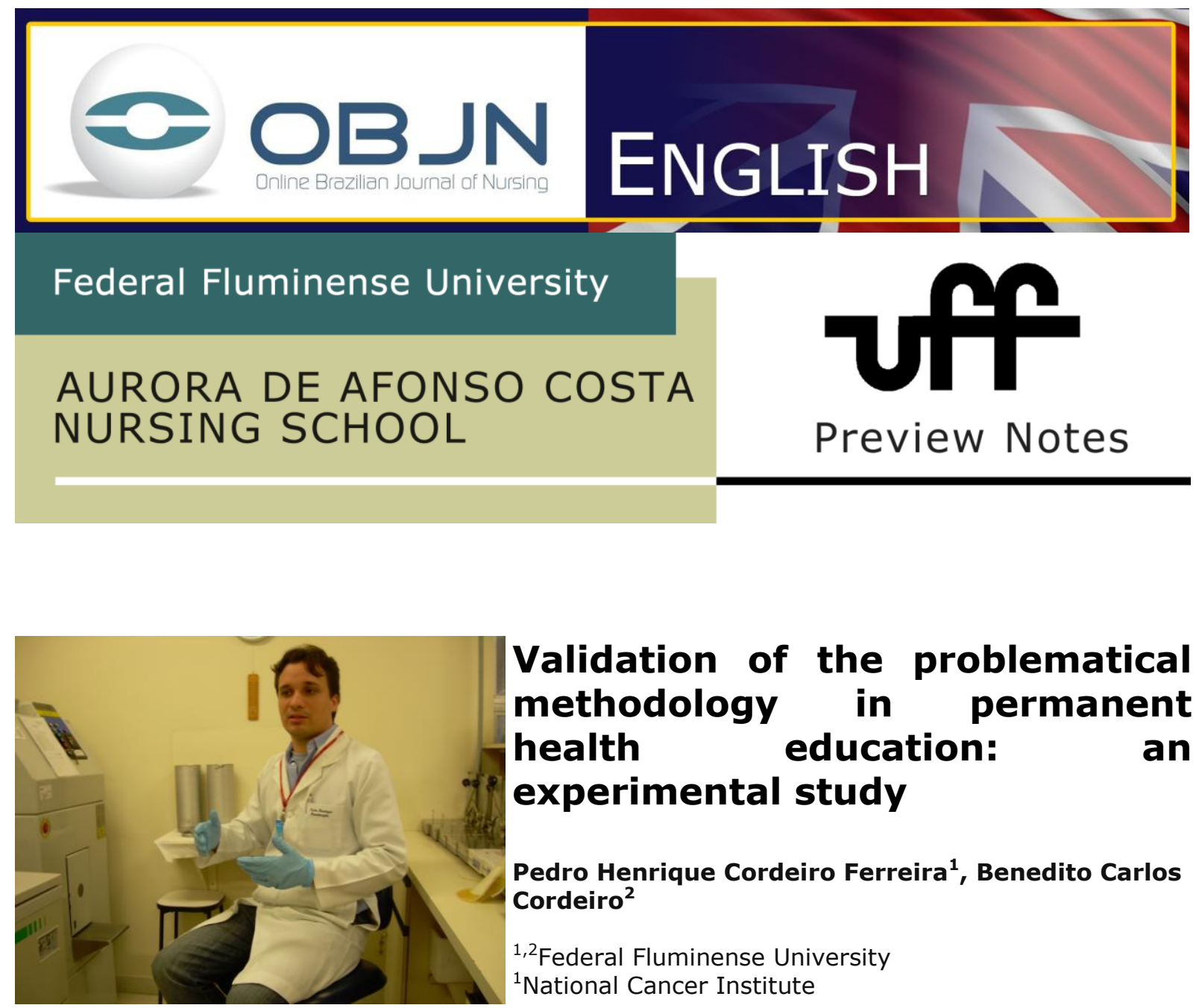

\title{
Validation of the problematical methodology in permanent health education: \\ an experimental study
}

Pedro Henrique Cordeiro Ferreira ${ }^{1}$, Benedito Carlos Cordeiro ${ }^{2}$

${ }^{1,2}$ Federal Fluminense University

${ }^{1}$ National Cancer Institute

\begin{abstract}
This is a research project for the Professional Master Program in Health Education from The Federal Fluminense University with the main aim to validate the problematical methodology in Permanent Health Education that is applied to hemocomponents. The specific aims are to exercise Hemotherapy Pharmaceutical Assistance, supported by an interdisciplinary approach in the context of SUS, and to obtain objective evidence that the problematical methodology is able to produce satisfactory results in the process of Permanent Education in Health. It is an experimental study with a quantitative approach to be performed in an oncology sector from a university hospital in the city of Rio de Janeiro. The subjects will be transfusion nurses and the ethical aspects will be respected in accordance with Resolution 196/1996.

Keywords: Pharmaceutical Services; Education, Continuing; Validation Studies; Problem-Based Learning.
\end{abstract}




\section{THE RESEARCH PROBLEM AND ITS SIGNIFICANCE}

Hemocomponents are highly critical drugs of intravenous infusion and under the Unified Health System (SUS) act directly in Hemotherapy Pharmaceutical Care, which comprises a set of education actions that aim to ensure that hemocomponents are processed and transfused within high standards of quality, safety and efficacy. Implementation of a model of Hemotherapy Pharmaceutical Care in SUS facilitates the development of an integrator and the quality of work between the pharmaceutical care, the transfusion nurse - the principal manager of the act of transfusion - and the patient ${ }^{(1)}$. Problematical methodology, or questioning, is one of the most eminent manifestations of constructivism in education. Paulo Freire emphasizes that problems of the study should be in a real scenario aiming to build knowledge from significant experiences ${ }^{(2)}$. In addition to creating favourable conditions for an effective interdisciplinary approach, the use of questioning in Permanent Healthcare Education provides positive factors to the quality of services, among which the subject's own personal growth works as a social commitment ${ }^{(3)}$. Understanding of the problematical methodology is important since method and teaching techniques are lacking in the literature with regards to validations that arise from studies constructed under a positivist perspective, whereby they are based on the use of statistical models to explain the reality. The author of this project, in the Hemotherapy Pharmaceutical Care role, proposes to carry out an interdisciplinary research study with nurses who administer blood products during actions of Permanent Healthcare Education in an oncology teaching hospital of the SUS. The objective of this research is to study the influence of problematical methodology in health professionals' learning.

\section{QUESTIONS}


How to validate the problematical methodology in the context of Permanent Education in Health?

What is the actual contribution of Hemotherapy Pharmaceutical Care for Permanent Education in Health in an interdisciplinary context?

\section{AIMS}

The principal aim of this research is to validate the problematical methodology in Permanent Healthcare Education applied to hemocomponents. More specifically, we aim to exercise Hemotherapy Pharmaceutical Assistance, supported by an interdisciplinary approach, in the context of the SUS and to obtain objective evidence that the problematical methodology is able to produce satisfactory results in the process of Permanent Education in Health.

\section{HYPOTHESES}

The study is based on the following assumptions:

$\mathrm{H} 1$ - The subjects that best evaluate the methodology of teaching (problematization) get better performance (level of learning) and;

$\mathrm{H} 2$ - The higher the level of student satisfaction with the teaching methodology used, the better their learning.

As a null hypothesis, we have:

H01 - There is no relationship between liking the methodology and its results;

H02 - The lower the level of satisfaction, the better the result.

\section{METHOD}

This is an experimental study with a quantitative approach, conducted during the program of Permanent Education in Hemotherapy that has been developed in an 
oncology teaching hospital from the SUS. The study subjects are transfusion nurses who will require individual authorization for the use of data evaluation tools for research purposes, by a Term of Free and Informed Consent, after consideration of the project and release of the opinion by the Ethics Committee of the institution in accordance with Resolution 196/1996. Data collection will consist of structured interviews and preliminary evaluation after the period of problematization with the hemocomponents theme. The statistical analysis of the data will be performed by multivariate analysis based on levels of learning of the theme and levels of subject satisfaction about the methodology used.

\section{REFERENCES}

1. Araújo FQ, Prado EM. Análise das Diretrizes Curriculares Nacionais do Curso de Graduação em Farmácia. Rev Contemp Educ. 2008; 3 (5): 96-108.

2. Torrezan RM, Guimarães RB, Furlanetti MPFR. A importância da problematização na construção do conhecimento em saúde comunitária. Trab educ saúde. 2012; 10 $(1) ; 2012$.

3. Lino MM, Backes VMS, Schmidt SMS, Ferraz F, Prado ML, Martins ST. The reality of nursing continuing education in the public health services: a descriptive study. Online braz $\mathrm{j}$ nurs [serial in the internet]. 2007 [cited 2012 jun 01]; 6(0). Available from: http://www.objnursing.uff.br/index.php/ nursing/article/view/619/147.

\section{PROJECT DATA}

Research from the Professional Master Program on Education in Health from Federal Fluminense University (Line 2: Permanent Education).

Guidance: Prof. Dr. Benedito Carlos Cordeiro.

Financial Support for Research: There is no financial support for this research.

Mailing Address: pferreira@inca.gov.br

Received: 04/07/2012

Approved: 04/09/2012 